\title{
Adhesion and Stability of Nanocellulose Coatings on Flat Polymer Films and Textiles
}

\author{
Raha Saremi ${ }^{1,2}{ }^{\oplus}$, Nikolay Borodinov ${ }^{3}$, Amine Mohamed Laradji ${ }^{1}{ }^{\infty}$, Suraj Sharma ${ }^{1,2}$, \\ Igor Luzinov ${ }^{3}$ and Sergiy Minko ${ }^{1,2, * \mathbb{i}}$ \\ 1 Nanostructured Materials Laboratory, University of Georgia, Athens, GA 30602, USA; raha@uga.edu (R.S.); \\ alaradji@wustl.edu (A.M.L.); ssharma@uga.edu (S.S.) \\ 2 Department of Textiles, Merchandising and Interiors, the University of Georgia, Athens, GA 30602, USA \\ 3 Department of Materials Science and Engineering, Clemson University, Clemson, SC 29634, USA; \\ nikolab@g.clemson.edu (N.B.); luzinov@clemson.edu (I.L.) \\ * Correspondence: sminko@uga.edu
}

Academic Editor: Sylvain Caillol

Received: 21 June 2020; Accepted: 13 July 2020; Published: 16 July 2020

\begin{abstract}
Renewable nanocellulose materials received increased attention owing to their small dimensions, high specific surface area, high mechanical characteristics, biocompatibility, and compostability. Nanocellulose coatings are among many interesting applications of these materials to functionalize different by composition and structure surfaces, including plastics, polymer coatings, and textiles with broader applications from food packaging to smart textiles. Variations in porosity and thickness of nanocellulose coatings are used to adjust a load of functional molecules and particles into the coatings, their permeability, and filtration properties. Mechanical stability of nanocellulose coatings in a wet and dry state are critical characteristics for many applications. In this work, nanofibrillated and nanocrystalline cellulose coatings deposited on the surface of polymer films and textiles made of cellulose, polyester, and nylon are studied using atomic force microscopy, ellipsometry, and T-peel adhesion tests. Methods to improve coatings' adhesion and stability using physical and chemical cross-linking with added polymers and polycarboxylic acids are analyzed in this study. The paper reports on the effect of the substrate structure and ability of nanocellulose particles to intercalate into the substrate on the coating adhesion.
\end{abstract}

Keywords: nanocellulose; polymer; coating; textile; adhesion

\section{Introduction}

Cellulose is the most abundant [1,2], renewable, biodegradable, and environmentally friendly organic material found in nature with great potential for the development of new applications with minimal health, environmental, or safety concerns [3]. Plant cell walls are composed of assembled cellulosic fibrils that are stabilized by intra- and interchain hydrogen bonds and van der Waals forces [4]. The fibrils are semicrystalline cellulose with 50-75\% crystalline regions [5]. The fibrils can be separated by mechanical [2,6-10], chemical [11-13], or a combination of both treatments [14] to make cellulose nanoparticles in the form of nanofibers (nanofibrillated cellulose, NFC) or whiskers (nanocrystalline cellulose, NCC) $[15,16]$ forming hydrogels in water. These nanoparticles, owing to their dimensions, shape, and high mechanical characteristics, attracted great interest in the engineering of nanostructured materials [14,17-21]. Nanocellulose-based materials, including coatings, were explored for many applications, such as packaging films [22-26], engineered composites [27], adsorbents [28], materials for health care [29], cosmetics [30], thermal insulation [31], paper [32], and filtration [33,34].

For time immemorial, one of the traditional application of the cellulosic material is the textile industry. Cotton, linen, hemp, and many other plant fibers are the major feedstock for the most 
demanded and comfortable cloth. In recent decades, there is a clear disposition for the shift from conventional clothing to smart textiles that integrate emerging technologies, such as communication devices, flexible electronics, and sensors [35]. Importantly, strong environmental and societal concerns demand a shift to the development of renewable and compostable materials along with sustainable technologies with minimal negative environmental impact [36]. A combination of wearable clothing systems and sustainability is advancing innovation in the traditional areas of textile manufacturing by endowing textiles with functional properties to address current health, safety, and environmental concerns associated with the textile industry.

Nanoscale dimensions and large specific surface of NFC and NCC allow them to intercalate into hierarchically organized fibrous structures, such as woven, knits, nonwoven, and composite textiles. Hence, nanocellulose materials can deliver functional molecules or particles bearing functionality covalently bonded or physically entrapped (caged) into a nanocellulose particle network. The functionalized NFC and NCC network is subsequently anchored to the textile surfaces via hydrogen/covalent bonds and physical interlocking. This method of functionalization of natural and synthetic fibers and fabrics is an environmentally sound approach without compromising the compostability and biocompatibility of the compostable textiles. For example, we have recently demonstrated that dyeing of textiles using NFC particles conjugated with commonly used reactive dyes can decrease the use of water, salts, and alkali by one order of magnitude with no change of the textile performance such as colorfastness referred to as conventional textile dyeing technology [37-39].

The key aspects of NFC and NCC textile coatings are adhesion and mechanical stability during dry (wearing due to abrasion) and wet (laundry) conditions. Cellulose has a natural self-adhesive characteristic, which relies primarily on interchain hydrogen bonding between hydroxyl groups of the adjacent cellulose chains and between cellulose chains and polymers of the textile, entanglements (specifically for NFC), and interlocking through the entanglement and intercalation into the fabric structures $[40,41]$. Many pretreatment methods such as plasma, ozone, and exposure to alkali solutions were successfully used for the materials incapable of the formation of hydrogen bonds with nanocellulose. For example, the treatment of polypropylene with ozone resulted in an improved adhesion to NCC owing to the hydrogen bonds with the oxidized surface of polypropylene bearing hydroxyl, carboxylic, and other oxygen-containing functional groups [42]. Nevertheless, strongly hydrogen-bonded nanocellulose materials swell in an aqueous environment $[43,44]$. The swelling can cause film degradation and loss of functional properties bound to the nanocellulose coatings. Therefore, it is important to understand the effect of nanocellulose swelling on the coating stability and develop methods for mitigating this problem.

This paper reports on a systematic study of adhesion and adhesion resistance to swelling (in water) of NFC and NCC thin film coatings on the surface of polymer films and fabrics made of cellulose (CL), cotton, poly(ethylene terephthalate) (PET), and nylon 6,6 (PA 6,6). We studied several methods for improvement of the adhesion and coating's stability, such as the use of a cationic polyelectrolyte poly(ethylene imine) (PEI), functional copolymers, and covalent cross-linking to elucidate major mechanisms for the improvement of the stability of nanocellulose coatings via combinations of adhesive and cohesive properties of the coatings. PEI is added to enforce the physical network of nanocellulose particles and nanocellulose-polymer substrate (films and textiles) interfaces via strong hydrogen bonds between primary and secondary amino groups of PEI and hydroxyl, amide, and ester groups of nanocellulose and textile materials (PET and nylon). A functional polymer-a copolymer of glycidyl methacrylate (GMA) and oligo(ethylene glycol) methacrylate (OEGMA) (P(GMA-OEGMA)) —was selected and synthesized based on the compatibility with nanocellulose hydrogels, the ability to form hydrogen bonds with cellulose, and functional epoxy groups to cross-link the polymer and form a network for reinforcing of the coating. Alternatively, a commonly used cellulose-crosslinking method with polycarboxylic acids was applied to probe the effect of cross-linking on the coating stability. 


\section{Results and Discussion}

\subsection{Fabrication of Uniform Nanocellulose Coatings on the Surface of Polymeric Materials}

The formation of nanocellulose coatings on the surface of fabrics is affected by the infiltration of nanocellulose hydrogels into a complex structure of the fabric. The permeation dynamics of hydrogels depends on the fabric density, structure of the yarn, interfacial tension, and rheological properties of the hydrogel. Many of these complications can be eluded using single filament fibers for coating, where the film formation is only limited by the wetting thermodynamics and rheology of the hydrogel. For low nanocellulose concentrations $(<1 \%)$, when the hydrogel viscosity is low, it spreads over the fiber surface and forms an enclosed nanocellulose coating upon evaporation of water, as can be observed from the scanning electron microscopy (SEM) images of the coated polyester, cotton, and nylon single fibers (Figure 1). The image of a nylon fiber (Figure 1c) exhibits a peeled off NFC film at the edge of the cut fiber surface visualizing the coating film morphology and thickness. The peeled fraction of the coating corroborates a uniform layer of NFC around the fiber surface.

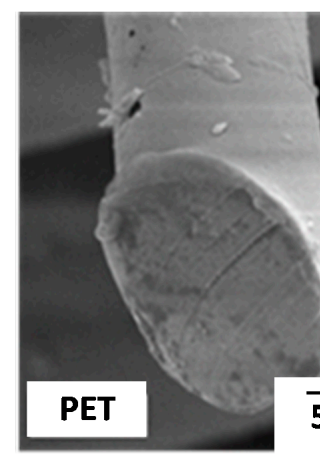

(a)

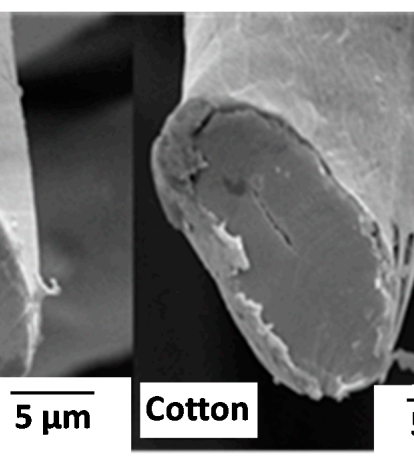

(b)

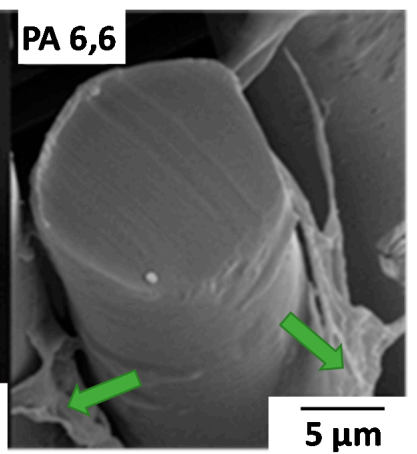

(c)

Figure 1. Scanning electron microscopy (SEM) images of (a) poly(ethylene terephthalate) (PET), (b) cotton, and (c) nylon 6,6 (PA 6,6) single fibers coated with nanofibrillated cellulose (NFC). Arrows point to the peeled fraction of the NFC coating.

The results of the experiments with single filament fibers show the formation of uniform smooth coatings over the fiber surface (Figure 1a,b). This uniform coating of NFC justifies the use of model flat substrates (e.g., polymer films) to probe morphology, adhesive behavior, and stability of nanocellulose coatings on the surfaces of different polymeric materials to monitor the coating structure and changes upon different treatment methods. Figure 2 exhibits differences in the surface morphology of NFC and NCC coatings on the Si-wafers. NFC coatings show a higher roughness owing to the higher particle size polydispersity in contrast to smoother and more uniform NCC coatings.

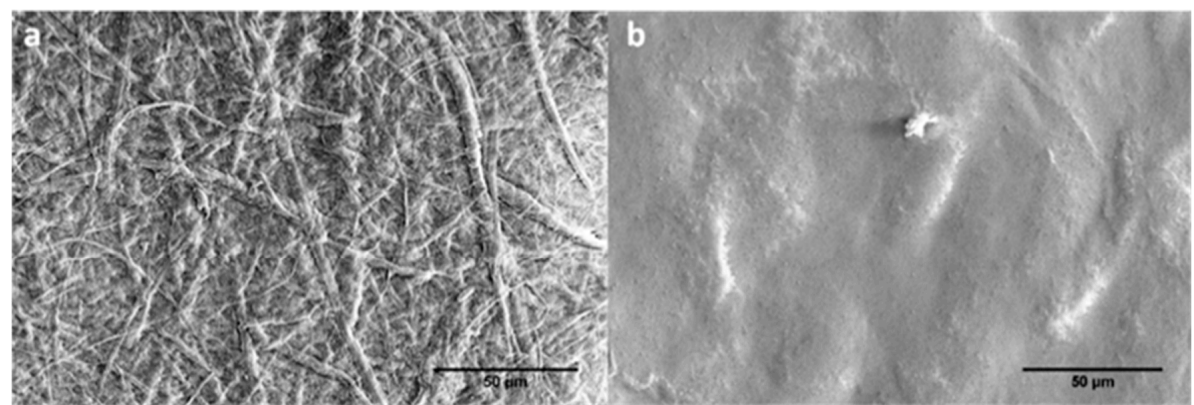

(a)

(b)

Figure 2. SEM images of the morphology of (a) NFC and (b) nanocrystalline cellulose (NCC) spin-coated on the Si-wafers. 
In this work, we used plane polymer films made of CL, PET, and PA 6,6 polymer solutions deposited on the surface of polished Si-wafers to minimize possible effects of the surface roughness of the substrate on the film formation. We prevented possible instabilities that could originate from a poor polymer-Si-wafer adhesion via the strengthening of the polymer-Si-wafer interactions by pretreatment of the Si-wafers with PEI polycations prior to deposition of the CL, PET, and PA 6,6 polymer films. Thickness and surface roughness of the polymer films were estimated with ellipsometry and atomic force microscopy (AFM) (Figure 3). The root mean square (RMS) roughness of the films did not exceed $7 \mathrm{~nm}$, with the highest roughness observed for the cellulose films.

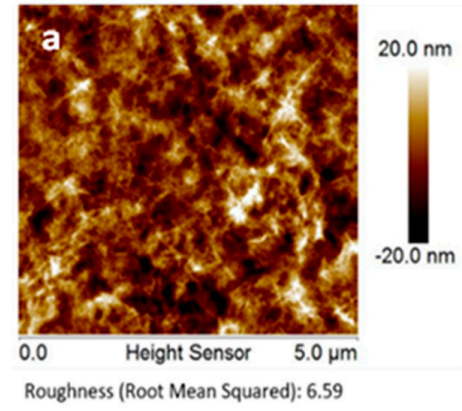

(a)

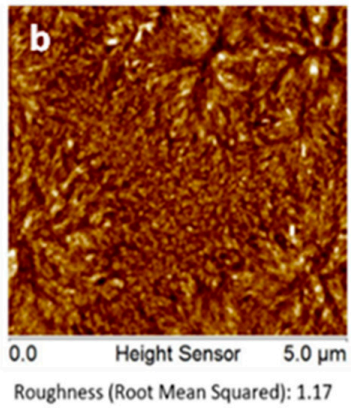

(b)
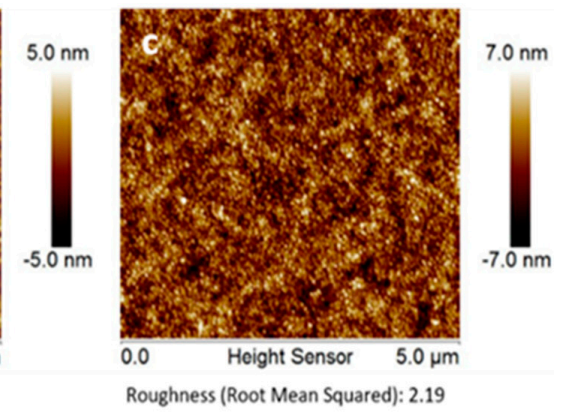

(c)

Figure 3. Representative atomic force microscopy (AFM) images of about 50-180 nm thick spin-coated films of (a) cellulose (CL), root mean square (RMS) roughness is $6.59 \mathrm{~nm}$; (b) nylon, RMS roughness is $1.17 \mathrm{~nm}$; and (c) PET, RMS roughness is $2.19 \mathrm{~nm}$ on the surface of the Si-wafers.

NFC and NCC films were deposited (spin-coated) on the surface of the polymer-coated Si-wafers using several different protocols (Figure S1). (i) Protocol 1: NFC and NCC aqueous dispersions were deposited on the CL, PET, and PA 6,6 coated Si-wafers; (ii) Protocol 2: NFC and NCC aqueous dispersions were deposited on the PEI pretreated CL, PET, and PA 6,6 coated Si-wafers; (iii) Protocol 3: NFC and NCC aqueous dispersions were mixed with PEI, and spin-coated on the CL, PET and PA 6,6 coated Si-wafers; and (iv) Protocol 4: NFC and NCC aqueous dispersions were mixed with P(GMA-OEGMA) copolymer, spin-coated on the CL, PET, and PA 6,6 coated Si-wafers. In all cases, the nanocellulose coatings were annealed after the deposition at $120^{\circ} \mathrm{C}$ for $1 \mathrm{~h}$.

The NFC and NCC coatings were prepared first using Protocol 1. We discovered a poor coverage of the PET and PA 6,6 surface with the nanocellulose materials. Then, we applied PEI pretreatment of all polymer substrates in Protocol 2 to improve wetting and coverage with nanocellulose. NFC- and NCC-coated samples from Protocol 2 are labeled as PEI-NFC and PEI-NCC, respectively.

Alternatively, we applied two different protocols to improve the adhesive and cohesive properties of nanocellulose coatings. According to Protocol 3, we mixed NFC and NCC hydrogels with PEI in solutions prior to the deposition on the polymer surfaces. Obtained by Protocol 3, NFC- and NCC-coated samples are labeled as NFC+PEI and NCC+PEI, respectively. Protocol 4 was used to mix NFC and NCC hydrogels with P(GMA-OEGMA) copolymer solutions; the samples were labeled as $\mathrm{NFC}+\mathrm{CP}$ and $\mathrm{NCC}+\mathrm{CP}$, respectively.

To summarize the nanocellulose coatings preparation, the resulting films are multilayered structures constituted of the Si-wafer substrate, a native $\mathrm{SiO}_{2}$ layer $(0.5-1 \mathrm{~nm}), \mathrm{PEI}$ adsorbed layer (typically 0.2-0.5 nm thick), polymer coating (CL, PET, or PA 6,6, typically 50-180 nm thick), and a nanocellulose (NFC or NCC) top layer with or without mixing with PEI or the copolymer. In some samples, the polymer layers are pre-coated with PEI (Protocol 2) before applying NC coatings. Representative 3D-plots for the layered structures obtained with imaging ellipsometry demonstrate uniform layered structure across the multicomponent coatings (Figure 4). 


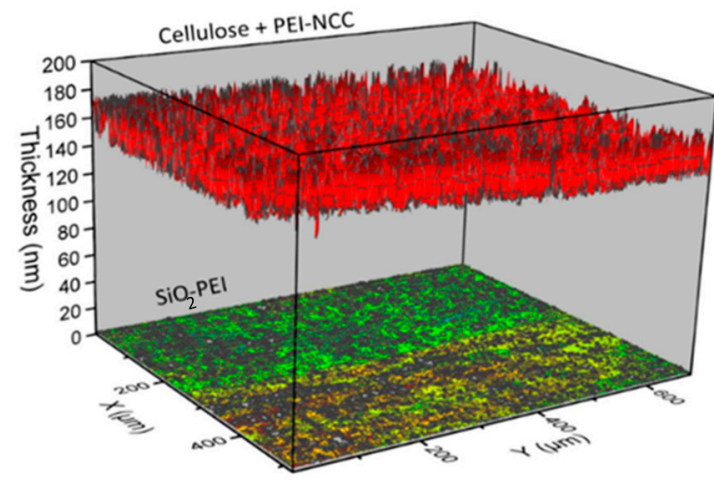

(a)

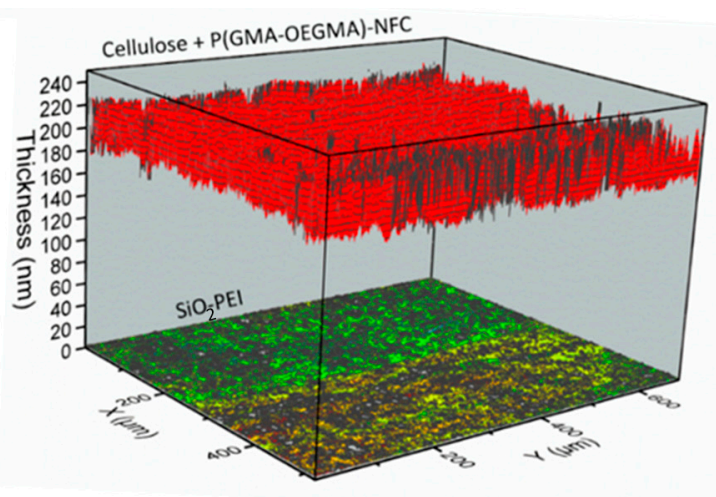

(b)

Figure 4. Representative examples of 3D-plots of layer-by-layer ellipsometric mapping of nanocellulose films on the polymer-coated Si-wafers constituted of the layers: (a) native $\mathrm{SiO}_{2}(1 \mathrm{~nm})$, poly(ethylene imine) (PEI) $(1 \mathrm{~nm})$, cellulose film $(150 \mathrm{~nm})$, PEI $(1 \mathrm{~nm})$, and NCC $(20 \mathrm{~nm})$; (b) native $\mathrm{SiO}_{2}(1 \mathrm{~nm})$, PEI $(1 \mathrm{~nm}), \mathrm{CL}(180 \mathrm{~nm})$, PEI $(1 \mathrm{~nm})$, and NFC-copolymer of glycidyl methacrylate (GMA) and oligo(ethylene glycol) methacrylate (OEGMA) (P(GMA-OEGMA)) mixture (40 nm).

\subsection{Mechanisms of the Nanocellulose Coating Degradation in a Wet State}

In aqueous solution, nanocellulose coatings become swollen owing to the strong hydrogen bonding of water molecules and cellulose [44]. The developed osmotic pressure, in combination with share forces, can cause complete defoliation of the coatings from the substrate surface or partial delamination. The prevalence of one of the two mechanisms of degradation is defined by the balance of adhesive and cohesive interactions in the film. The complete or very large depletion of the film materials is likely associated with adhesive failure, while fractional losses or partial delamination of the coating film are caused by cohesive failure.

The stability of the deposited NFC and NCC films in an aqueous environment was estimated with a simple test. The coated samples were exposed to $50{ }^{\circ} \mathrm{C}$ aqueous solution at stirring for $1 \mathrm{~h}$. Comparing the AFM images of the film before and after exposure to the aqueous medium in most cases did not reveal changes in the film morphology (Figure 5). For these nanocellulose coatings, we monitored changes in average film thickness. Only in the case of very poor adhesion, as for untreated PET and some PA 6,6 substrates, the AFM images demonstrate a low surface coverage by NFC and NCC, respectively (Figures 6 and 7). For these coatings, we monitored the surface coverage using an AFM "flooding analysis"—a statistical method where the polymer coating layer is set as a threshold and the surface areas of all other structures above the threshold are added to estimate the overall coverage with the nanocellulose material. 


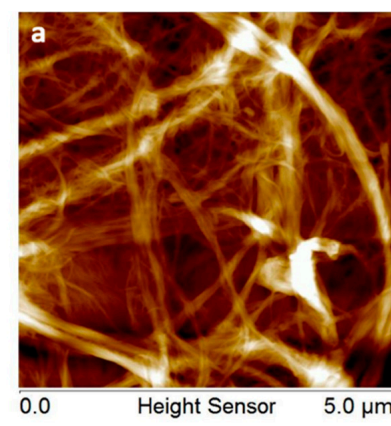

(a)

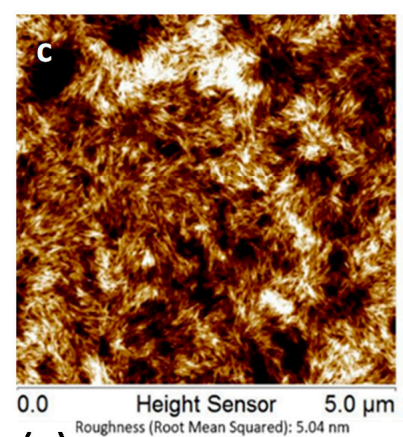

(c)

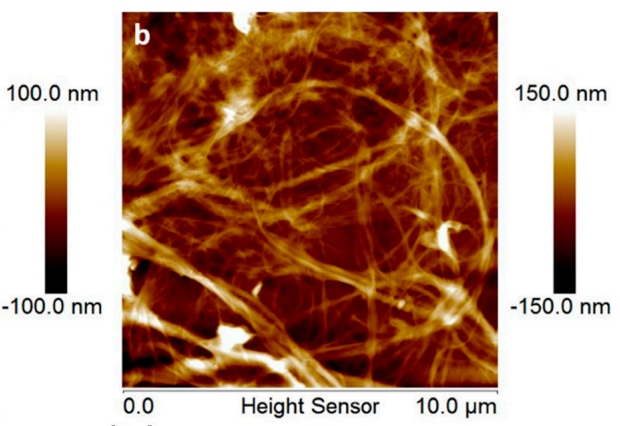

(b)

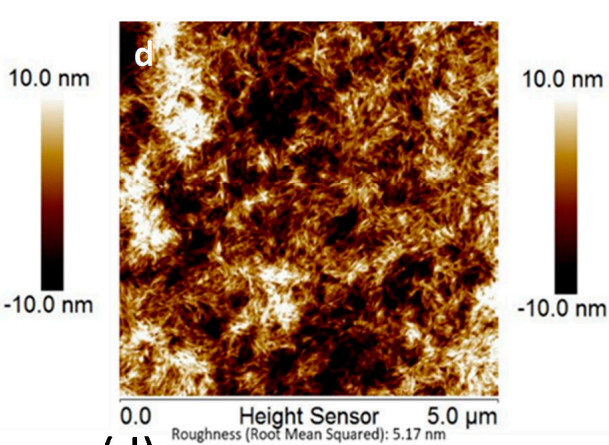

(d)

Figure 5. AFM topography images of nanocellulose coatings (a,b) PEI-NFC and (c,d) NCC+PEI on $(\mathbf{a}, \mathbf{c})$ PA 6,6 as-deposited and (b,d) after rinsing in water.
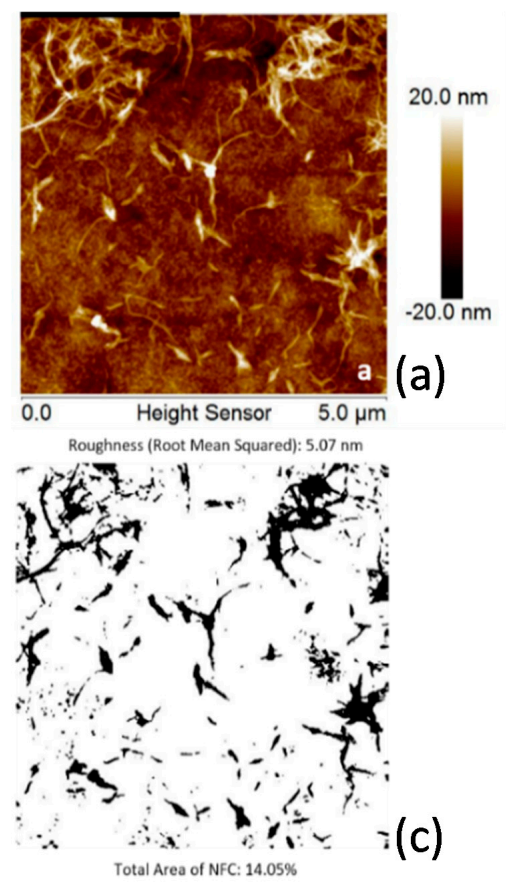
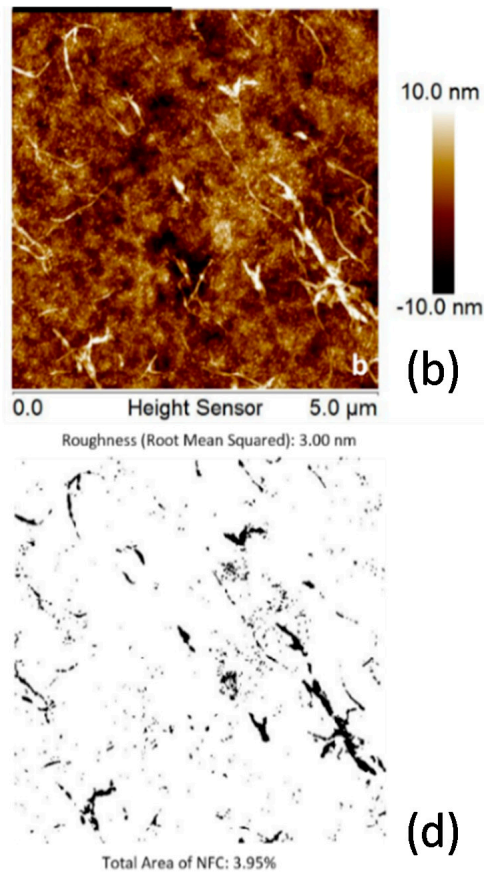

Figure 6. AFM images of NFC coatings on PET $(\mathbf{a}, \mathbf{c})$ as-deposited and $(\mathbf{b}, \mathbf{d})$ after rinsing in water: $(\mathbf{a}, \mathbf{b})$ topography images and $(\mathbf{c}, \mathbf{d})$ flooding analysis images showing the surface coverage by NFC particles (dark areas). 

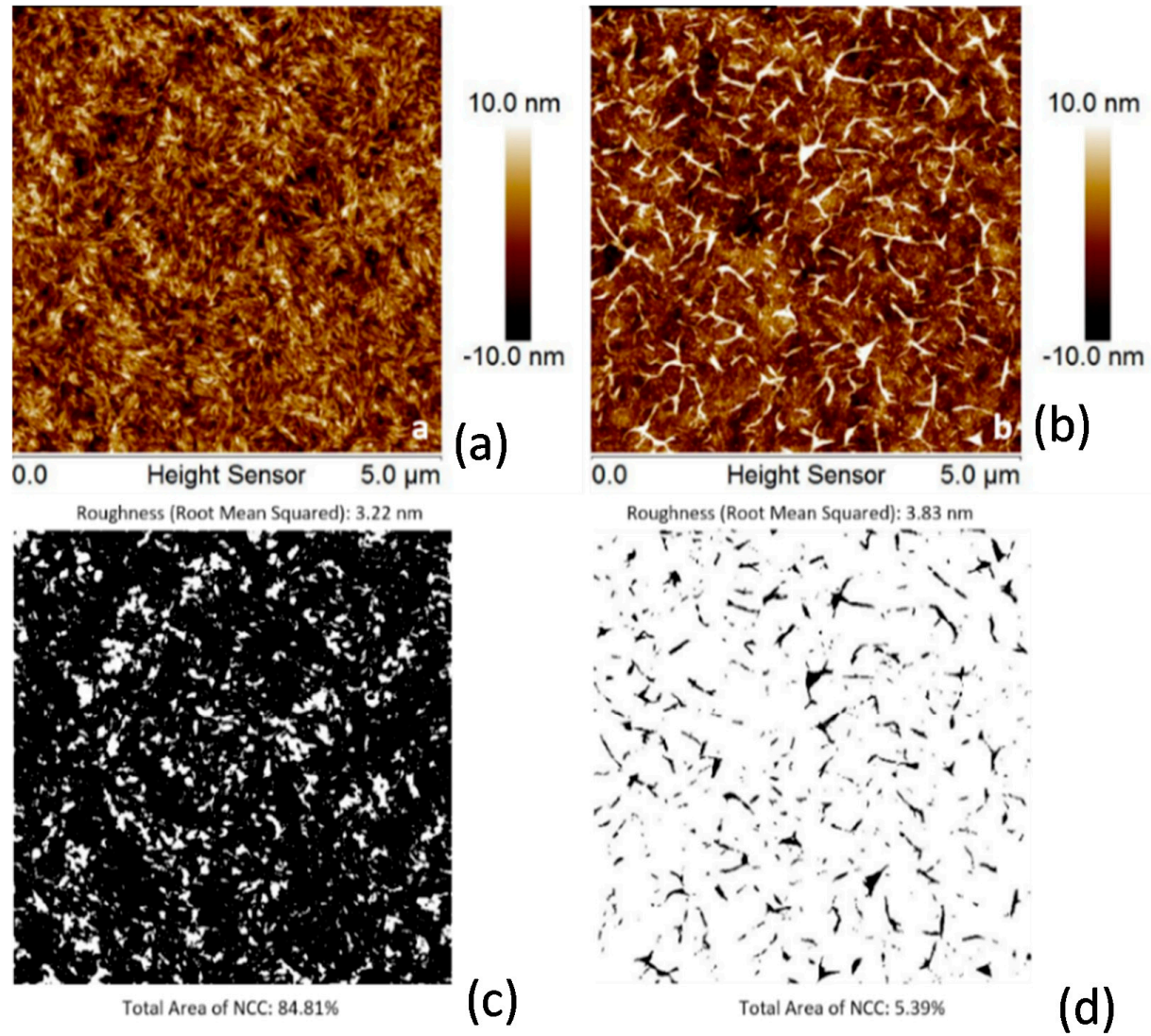

Figure 7. AFM images NCC coatings on PET as-deposited $(\mathbf{a}, \mathbf{c})$ and after rinsing in water $(\mathbf{b}, \mathbf{d})$ : topography images $(\mathbf{a}, \mathbf{b})$ and flooding analysis images showing the surface coverage by NCC particles $(\mathbf{c}, \mathbf{d})$.

Changes in film thickness of the NFC and NCC coatings in all cases, with exceptions of untreated PET substrates, after rinsing in water, are reported in Table 1 as a percent (\%) of the detached coating materials. For untreated PET substrates, the results report changes of the surface coverage using the flooding method. The coating thickness prepared by a spin-coating method depends on the rheological characteristics of NFC and NCC hydrogels and wetting of the polymer films. The rheological properties of the hydrogels depend on the concentration and presence of additives. Consequently, we analyze the relative changes in film thickness prepared using different modification methods.

Table 1. Changes in thickness (surface coverage) of nanofibrillated cellulose (NFC) and nanocrystalline cellulose (NCC) coatings on the surfaces of cellulose (CL), poly(ethylene terephthalate) (PET), and nylon 6,6 (PA 6,6) after rinsing in water. PEI, poly(ethylene imine); P(GMA-OEGMA), copolymer of glycidyl methacrylate (GMA) and oligo(ethylene glycol) methacrylate (OEGMA).

\begin{tabular}{ccccccc}
\hline \multirow{2}{*}{ Sample } & \multicolumn{5}{c}{$\begin{array}{c}\text { Film Thickness, H, and A fraction of Washed-Out Coating } \\
\text { from Different Substrates, F (10\% Error) }\end{array}$} \\
\cline { 2 - 7 } & \multicolumn{3}{c}{ CL } & \multicolumn{2}{c}{ PET } & \multicolumn{2}{c}{ PA $\mathbf{6 , 6}$} \\
\hline H, $\mathbf{n m}$ & $\mathbf{F , ~ \%}$ & $\mathbf{H , ~} \mathbf{n m}$ & $\mathbf{F}, \mathbf{\%}$ & $\mathbf{H}, \mathbf{n m}$ & $\mathbf{F}, \mathbf{\%}$ \\
\hline NFC & 50 & 68 & non-uniform & 71 & non-uniform & 40 \\
PEI-NFC & 46 & 22 & 42 & 18 & - & - \\
NFC+PEI & 20 & 70 & 77 & 81 & 53 & 37 \\
NFC+P(GMA-OEGMA) & 33 & 77 & - & - & 401 & 25 \\
NCC & 21 & 5 & non-uniform & 93 & non-uniform & 93 \\
PEI-NCC & 89 & 53 & 113 & 60 & - & - \\
NCC+PEI & 40 & 25 & 77 & 12 & 65 & 77 \\
NCC+P(GMA-OEGMA) & 8 & 11 & 80 & 1 & 133 & 2 \\
\hline
\end{tabular}


The analysis of the experimental data shows that the most common mechanism of coating degradation is partial delamination. Only for the PET substrate, we observed almost a complete adhesive detachment of the nanocellulose. The result shows that the nanocellulose coating has the lowest adhesion to the PET surface and the strongest interaction with the PA 6,6 surface among the synthetic polymers. NCC coatings demonstrate a higher adhesion to different CL substrates than NFC coatings. It is likely owing to the denser packed NCC particles in the coating in contrast to NFC fibers, and hence a lower swelling of the coating. The addition of PEI and P(GMA-OEGMA) improves the stability of the coatings. The latter effect is likely owing to the switching from the adhesive defoliation mechanism to the partial delamination of the film.

Notably, the film is much more stable on PET and PA 6,6 substrates when the coating is mixed with P(GMA-OEGMA). We may speculate that the major strengthening contribution of the copolymer is in the improvement of the cohesive properties of the film. The much greater thickness of the mixed films supports this conclusion.

We may speculate about the following mechanism of the improvement of the stability of the coating in an aqueous environment. Cationic anchoring polymers bearing amino-functional groups are used to treat different substrates for improvement in their interaction with cellulose [45-53]. Cationic polyelectrolytes interact with cellulose coatings through an electrostatic, donor-acceptor type of interactions, and hydrogen bond formation [45]. Nanocellulose, cotton, and polyester fibers are negatively charged in an aqueous environment, whereas nylon possesses amphoteric properties. In all cases, swollen in water, nanocellulose materials and polymers experience repulsive electrostatic forces. These repulsive interactions could be compensated by surface modification of the interacting materials with polycations such as PEI [52]. However, an excess of PEI will result in an overcharge of the surfaces, and repulsion between negatively charged materials will be replaced by repulsion among positively charged materials in water. PEI and other polyelectrolytes may also enhance swelling of the coatings in water. The results show no benefits of the use of PEI for the treatment of cotton and nylon fabrics; however, the interaction with PET is slightly improved. The latter is explained by poor hydrogen bonding between PET and nanocelluloses, which can be improved owing to the PEI-PET interactions.

P(GMA-OEGMA) copolymer bears ethylene oxide and epoxy functional groups. These two types of functional groups provide a combination of strong hydrogen bonds and covalent cross-linking. The covalent cross-linking mechanism involves the opening of epoxy rings and the formation of covalent bonds between epoxy groups of P(GMA-OEGMA) [54]. Reactivity of cellulosic -OH with epoxy-groups is not high enough to provide substantial effect for the cross-linking involving nanocellulose [55]. However, surface carboxylic functional groups that may be present because of oxidative degradation in the process of the production of nanocellulose could interact with epoxy groups and form covalent cross-links. The nanocellulose and P(GMA-OEGMA) copolymer blends upon drying, and thermal annealing will form an interpenetrated network owing to the covalently cross-linked polymer and physical cross-links via hydrogen bonds of nanocellulose materials. These two interpenetrating networks are also co-cross-linked via some fraction of carboxylic groups on the surface of cellulose. Epoxy groups secure good adhesion to various polar substrates. The experiments show that the presence of the copolymer improves adhesion to PET and nylon surfaces. In all experiments, we observe the obvious improvement of the nanocellulose coating stability in the presence of the copolymer.

\subsection{Adhesive Behavior of Nanocellulose Coatings}

Mechanical stability of the nanocellulose coating in the dry state is another important property for practical applications. Upon mechanical forces, the coating could be peeled off the polymer surface (adhesive failure) or partially delimited (cohesive failure). Hence, the coating performance can be analyzed using similar concepts of the degradation mechanisms, as was discussed for the aqueous environment. For the experiments, we used T-peel tests. Two identical materials were adhered using NFC or NCC hydrogels sandwiched between the materials, followed by drying and annealing the samples. These tests were performed in two series of experiments. In the first series, NFC and NCC 
were used to bind two identical samples of cellophane, PET, and PA 6,6 polymer films. In the second series of experiments, NFC and NCC were used to bind two identical samples of cotton, PET, and PA 6,6 fabrics. The NFC and NCC coatings on the polymer films and fabrics were prepared using the same Protocols 1-4 as in the tests of the stability of the coating in water.

The results of the peel tests with the polymer films show similar tendency as for the experiments on the coating stability in water; that is, NCC demonstrates a higher strength as compared with NFC, and the interaction with PET is the lowest among other polymers (Figure 8). However, in contrast with the experiments in water, nanocellulose interactions with the cellophane film are much stronger than with nylon. This difference in adhesion between nanocellulose materials and cellulose substrates in the dry state and in water provides evidence that the nanocellulose coating degradation in water is affected by swelling of the coating and weakening of the interfacial hydrogen bonds, while in the dry state, the intermolecular interactions remain strong.

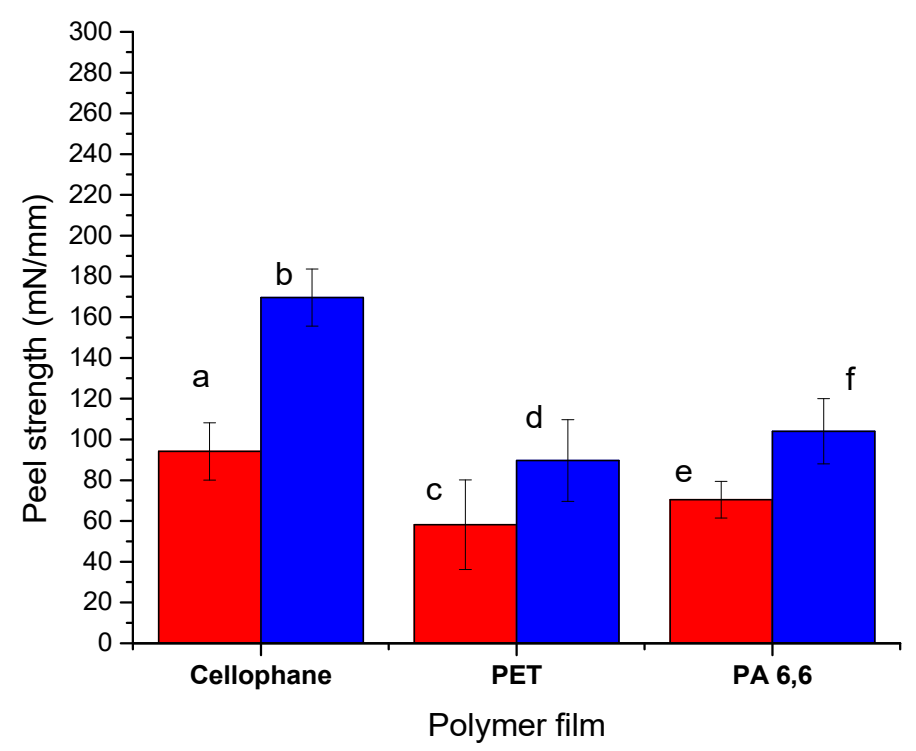

Figure 8. Peel strength for polymer films made of cellophane, PET, and PA 6,6 adhered with (a,c,e) NFC and $(\mathbf{b}, \mathbf{d}, \mathbf{f})$ NCC.

The outcomes changed for the peel tests using fabrics instead of films made of the same polymers. NCC binding is stronger than NFC for all cases (compare Figures 9 and 10). We observe that the peel strength increases in the order cotton $<$ PET $<$ PA 6,6 for NFC and NCC. For both types of nanocelluloses, the pretreatment with PEI and mixing with the copolymer improves the peel strength. Similar conclusions about peel strength are applied to a blended (50:50) cotton-PET fabric (Figure 11). The most surprising result is the lowest peel strength for cotton textiles. This result was in conflict with the experiment in water (Table 1) and with the peel test for polymeric films (Figure 8) when NFC and NCC coatings showed the strongest stability and adhesion to the cellulose substrates. We hypothesized an additional factor that may impact the peel strength is the structure of the fabrics or the ability of nanocellulosic materials to infiltrate the fabric structure. The latter will result in a greater contact area between the fabric and nanocellulose and the formation of mechanical interlocks between intercalated fibrillary structures. 


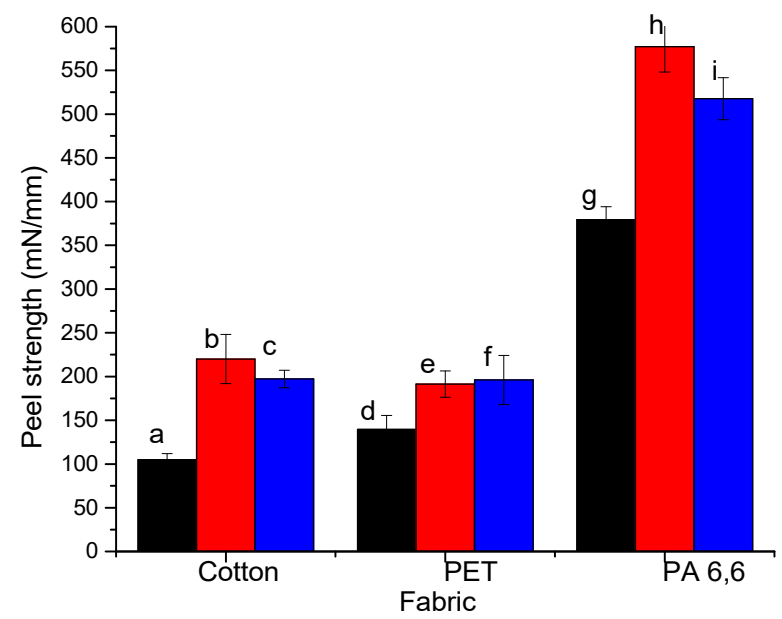

Figure 9. Peel strength for cotton, PET, and PA 6,6 fabrics adhered using NFC: (a,d,g) NFC with no additives, (b,e,h) NFC+PEI, and (c,f,i) NFC+P(GMA-OEGMA) mixtures.

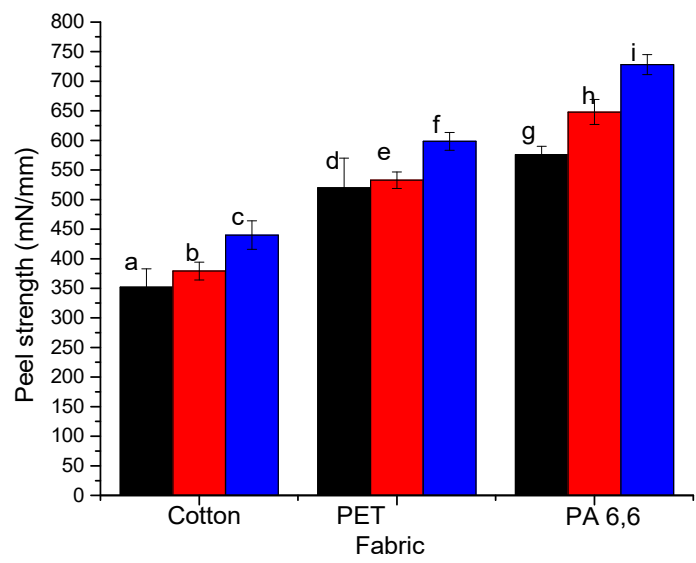

Figure 10. Peel strength for cotton, PET, and PA 6,6 fabrics adhered using NCC: (a,d,g) NCC with no additives, (b,e,h) NCC+PEI, and (c,f,i) NCC+P(GMA-OEGMA) mixtures.

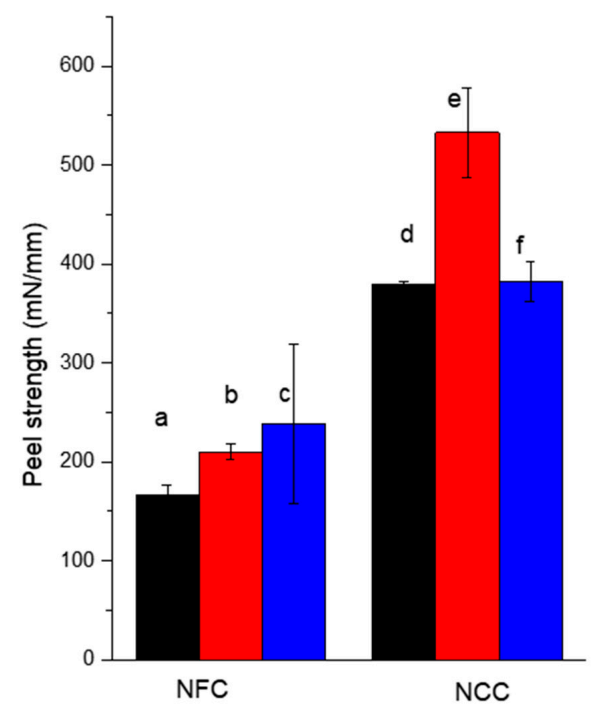

Figure 11. Peel strength for cotton-PET (50:50) fabric blend adhered with (a,d,c) NFC and (d-f) NFC: (a,d) with no additives, (b) NFC+PEI, (e) NCC+PEI, (c) NFC+P(GMA-OEGMA), and (f) NCC+P(GMA-OEGMA) mixtures. 
This hypothesis was verified with the analysis of the structure and porosity of the fabrics. The warp and weft density and mean flow pore diameter (MFPD) of the fabrics are presented in Table 2 . The result indicates that warp and weft density for cotton fabrics are substantially higher than those for other samples. While warp densities between polyester, nylon, and cotton/polyester are similar, the weft density of nylon is the lowest among the samples. Fabrics with higher weft density are less permeable for functional additives [56]. This structural property explains the highest peel strength for nylon and the lowest for the cotton fabrics.

Table 2. Structural characteristics of the fabrics. MFPD, mean flow pore diameter.

\begin{tabular}{cccc}
\hline Samples & $\begin{array}{c}\text { Warp Density, } \\
\text { Yarns/cm }\end{array}$ & $\begin{array}{c}\text { Weft Density, } \\
\text { Yarns/cm }\end{array}$ & MFPD, $\boldsymbol{\mu m}$ \\
\hline Cotton & 33 & 29 & 67 \\
Polyester & 22 & 17 & 18 \\
Nylon & 20 & 11 & 64 \\
Cotton/Polyester (50\%/50\%) & 21 & 19 & 40 \\
\hline
\end{tabular}

The mean flow pore diameter of the cotton and nylon fabrics also shows the highest values with broader pore size distribution in nylon fabric. This is another factor correlating with the uptake of NFC and NCC into the fabrics. Polyester has the lowest MFPD of $18 \mu \mathrm{m}$, but the weft density of 17 yarns/cm makes the fabric less dense for the infiltration of nanocellulose hydrogels into the fabrics, contributing to the higher peel strength as compared with the cotton fabric.

For the cotton fabric, the pore size ranges from 10 to $128 \mu \mathrm{m}$, while for the nylon fabric, the range is very broad, and the pore size reaches $\sim 200 \mu \mathrm{m}$. The cotton/polyester blend pore size distribution shows that the majority of the pores are less than $\sim 100 \mu \mathrm{m}$, and for the PET fabric, the pore size range is between $\sim 5$ and $\sim 50 \mu \mathrm{m}$. The pore size distributions of the cotton, polyester, nylon, and cotton/polyester blended fabrics are shown in Figures S3-S6. The peel test results correlate with pore size distribution as the highest peel strength is observed for the nylon fabrics with a skew distribution towards large size pores.

\subsection{Covalent Cross-Linking of Nanocellulose Coatings}

An alternative approach to stabilize nanocellulose coatings is the cross-linking of NFC and NCC particles. Cross-linking of cotton fabrics is a widely used method to fabricate wrinkle resistance cotton products. Polycarboxylic acids for cross-linking of cotton cellulose were first introduced in the 1960s. The cross-linking can be catalyzed with sodium hypophosphite $\mathrm{NaH}_{2} \mathrm{PO}_{2}$ [57-62]. Polycarboxylic acids, for example, maleic acid (MA), in the presence of sodium hypophosphite, form ester bonds with cellulose hydroxyls at $160-180{ }^{\circ} \mathrm{C}[63,64]$. The formation of the cross-links is confirmed by the appearance of the ester carbonyl band at 1720 and $1718 \mathrm{~cm}^{-1}$ (Figure S7).

The results of the peel tests for the cross-linked NFC and NCC coatings on the cotton fabric are shown in Figure 12. For both nanocellulose materials, the cross-linked system is stronger as compared with the reference non-cross-linked materials. However, the results are comparable to those obtained with P(GMA-OEGMA) copolymer. The results with cross-linked nanocellulose materials on the cotton fabric are compared to those on the cellophane film in Figure 12. This comparison reveals the synergistic effect of cross-linking and infiltration of nanocellulosic materials into the fabric structure. Smaller NCC particles infiltrate into the dense cotton fabric structure more efficiently as compared with NFC. This infiltration results in an increased adhesive interface. At the same time, the infiltration underlines the contribution of the mechanical interlocking enforced by the cross-linking of the cellulosic materials. 


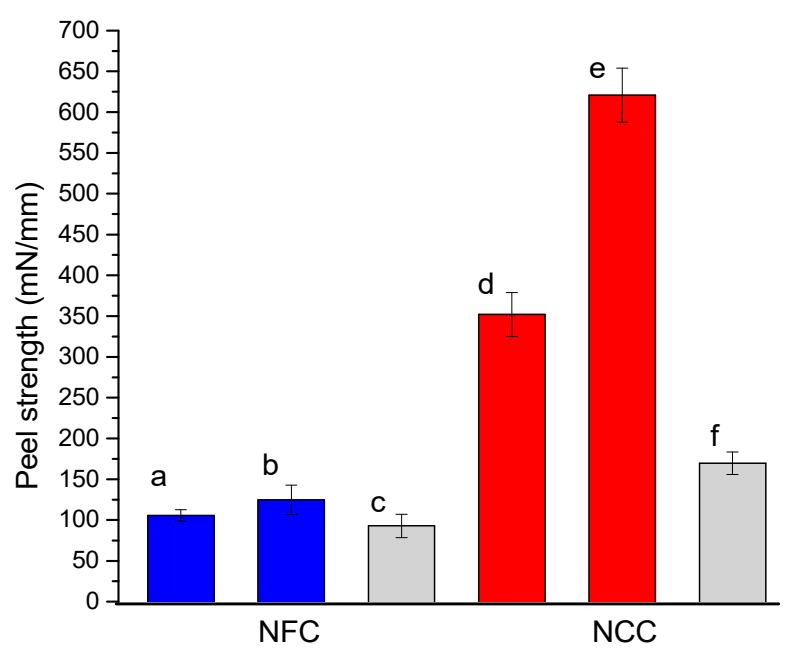

Figure 12. Peel strength for cotton textiles adhered with $(\mathbf{a}, \mathbf{b})$ NFC and $(\mathbf{d}, \mathbf{e})$ NCC with (a,d) no cross-linking and $(\mathbf{b}, \mathbf{e})$ with covalent cross-linking using MA compared with (c) NFC and (f) NCC adhered cellophane films.

\section{Materials and Methods}

\subsection{Materials}

Nanofibrillated cellulose hydrogel $(2 \%)$ was prepared as previously reported using a mechanical homogenization method [37,38]. Nanocrystalline cellulose hydrogel $(11.9 \%)$ was purchased from the Process Development Center, University of Maine. m-Cresol, lithium chloride, $\mathrm{N}, \mathrm{N}$-dimethylacetamide, chlorobenzene, phenol, polyethylenimine (PEI) (number average molecular mass $\mathrm{Mn}=60 \mathrm{~kg} / \mathrm{mol}$ ), maleic acid (MA), sodium hypophosphite, glycidyl methacrylate (GMA, 97\%), azoisobutyronitrile (AIBN), oligo (ethylene glycol) methyl ether methacrylate (OEGMA, $\mathrm{Mn}=950 \mathrm{~g} / \mathrm{mol}$, stabilized with inhibitors), and inhibitor removers (kits for removing hydroquinone and monomethyl ether hydroquinone (MEHQ) and tert-butylcatechol (BHT)) were purchased from Sigma-Aldrich (St. Louis, MO, USA).

Silicon wafers (100 crystal plane) with a native oxide layer were purchased from University Wafer (South Boston, MA, USA). A polyethylene terephthalate (PET) film (0.50 mm thick) and a nylon 6,6 (PA 6,6) film (0.5 mm thick) were purchased from GoodFellow, Coraopolis, PA, USA. A cellophane film (regenerated cellulose) $0.03 \mathrm{~mm}$ thick was provided by Thermetrics. Cotton (100\%, plain weave), nylon 6,6 (100\%, spun, plain weave), cotton/polyester, PET (50\%/50\%, plain weave), polyester, and PET (100\%, spun, plain weave) fabrics were purchased from Testafabrics, Inc., West Pittston, PA, USA.

\subsection{Synthesis of $P(G M A-O E G M A)$ Copolymer}

P(GMA-OEGMA), a random copolymer of glycidyl methacrylate (GMA) and oligo(ethylene glycol) methacrylate (OEGMA), $\mathrm{M}_{\mathrm{W}}=2000 \mathrm{~kg} / \mathrm{mol}$, was synthesized by solution free-radical polymerization $[65,66]$. The inhibitor MEHQ and BHT removers were added to purify GMA and OEGMA for $45 \mathrm{~min}$ each. After filtration and purging with nitrogen for $45 \mathrm{~min}$, the monomer solution $(0.5 \mathrm{M})$ at GMA/OEGMA + 1:4 in MEK was used for polymerization initiated by $0.01 \mathrm{M}$ AIBN at $50{ }^{\circ} \mathrm{C}$ for $1.5 \mathrm{~h}$. The copolymer was extracted and purified by repetitive precipitation (three times) in diethyl ether. The copolymer was stored in a MEK solution in the absence of light. According to an NMR analysis (Bruker AVANCE-300, Billerica, MA, USA), the copolymer composition is $66 \mathrm{~mol} \%$ (93 $\mathrm{wt} \%$ ) OEGMA and $34 \mathrm{~mol} \%$ GMA. The copolymer is characterized by a glass transition temperature of $-50{ }^{\circ} \mathrm{C}$ and a melting temperature of $35^{\circ} \mathrm{C}$ (DSC2920, TA Instruments, New Castle, DE, USA). The copolymer is soluble in water. 


\subsection{Preparation of Polymer Substrates for Nanocellulose Deposition}

Si-wafers were cut into square pieces $(1 \mathrm{~cm} \times 1 \mathrm{~cm})$ and then cleaned in a solution of $28 \%$ $\mathrm{NH}_{4} \mathrm{OH} / 30 \% \mathrm{H}_{2} \mathrm{O}_{2} / \mathrm{H}_{2} \mathrm{O}(1: 1: 1)$ at $65^{\circ} \mathrm{C}$ for $1 \mathrm{~h}$. They were rinsed with deionized water (DI) water and dried under a flux of argon gas. The cleaned wafers were dipped into a solution of PEI (1\%) for $15 \mathrm{~min}$ and rinsed with DI water and dried with argon gas. The resulting modified silicon wafers were stored at room temperature in a clean desiccator.

PET was dissolved in a solution of phenol-chlorobenzene $(1: 1)$ in a boiling water bath $\left(100{ }^{\circ} \mathrm{C}\right)$. Once fully dissolved, $20 \mu \mathrm{L}$ of the solution was spin-coated (3000 rpm for $20 \mathrm{~s}$ ) on the Si-wafers. The substrates were transferred to an oven heated at $180{ }^{\circ} \mathrm{C}$ and annealed for $24 \mathrm{~h}$ to remove the residual solvent.

PA 6,6 was dissolved in m-cresol at $100{ }^{\circ} \mathrm{C}$ by stirring for several hours. The nylon films were prepared by spin-coating (3000 rpm for $20 \mathrm{~s}$ ) $20 \mu \mathrm{L}$ of the solution on the Si-wafers. The substrates were immediately transferred to an oven and dried at $180{ }^{\circ} \mathrm{C}$ for $24 \mathrm{~h}$.

Cellulose films were prepared by heating of a cellulose powder in a solution of lithium chloride ( $\mathrm{LiCl}, 1-3 \%$ ) and N,N-dimethylacetamide (DMAc, 3-9\%) to $150{ }^{\circ} \mathrm{C}$, and then allowed the solution to cool slowly to room temperature [67,68]. Afterward, $20 \mu \mathrm{L}$ of the cellulose solution was spin-coated (3000 rpm for $10 \mathrm{~s}$ ) onto the cleaned Si-wafers. The samples were submerged in DI water for $20 \mathrm{~min}$ to remove the remaining $\mathrm{LiCl}$; they were dried with argon gas and heated for $20 \mathrm{~min}$ at $180{ }^{\circ} \mathrm{C}$ to allow for the evaporation of any residual solvent. The samples were stored at room temperature.

\subsection{Nanocellulose Coatings on Si-Wafers and Polymer-Coated Si-Wafers}

NFC and NCC films were prepared by spin-coating (3000 rpm for $30 \mathrm{~s}$ ) $20 \mu \mathrm{L}$ of the diluted NFC and NCC hydrogels (1\%) onto the substrates (Si-wafers and cellulose, PET, and PA 6,6 coated Si-wafers) and annealed at $120^{\circ} \mathrm{C}$ for $24 \mathrm{~h}$.

Nanocellulose coatings were prepared on the surface of CL, PET, and PA 6,6 coated Si-wafers after pretreatment of the substrates with PEI or P(GMA-OEGMA). These samples were labeled as PEI-NFC and PEI-NCC, respectively. These samples were prepared by submerging of the polymer-coated Si-wafers into a 1\% PEI solution for $30 \mathrm{~min}$. Then, the samples were rinsed with DI water and dried with argon gas. NFC and NCC solutions were spin coated (3000 rpm $30 \mathrm{~s}$ ). The samples were annealed at $120^{\circ} \mathrm{C}$ for $1 \mathrm{~h}$.

Alternatively, NFC (0.1\%) and NCC (1\%) were mixed with a 1\% PEI or P(GMA-OEGMA) solution (20:1 by volume) and stirred for $1 \mathrm{~h}$, for nanocellulose-PEI and nanocellulose- P(GMA-OEGMA) blends, respectively. Then, $20 \mu \mathrm{L}$ of the PEI-modified or P(GMA-OEGMA)-modified hydrogels was spin-coated onto the polymer-coated Si-wafers and dried at $120^{\circ} \mathrm{C}$ for $1 \mathrm{~h}$. These samples were labeled $\mathrm{PEI}+\mathrm{NFC}, \mathrm{PEI}+\mathrm{NCC}, \mathrm{CP}+\mathrm{NFC}$, and CP+NCC, for NFC and NCC mixed coatings, respectively.

\subsection{Characterization of Coatings}

Scanning electron microscopy (SEM) imaging was carried out using an FEI Teneo (FEI Co., Hillsboro, OR, USA), a field emission scanning electron microscope. Atomic force microscopy (AFM) images were obtained using a Bruker Multimode Nanoscope instrument (Bruker, Billerica, MA, USA) with the ScanAssyst-Air probe (Bruker) spring constant $0.4 \mathrm{~N} / \mathrm{n}$, a silicon oxide tip). All the measurements were performed under ambient conditions at room temperature and at relative humidity (RH) of 50-55\%. All AFM data analysis and data processing were done with the NanoScope Analysis software version 1.40 (Bruker).

The thickness of the films at three different locations for each sample after the deposition of each layer on the substrates was measured by a single wavelength imaging ellipsometer ep4sw (Accurion, Göttingen, Germany) with a fixed angle of incidence of $70^{\circ}$. Ellipsometry thickness maps were generated using the Accurion software package, DataStudio, for selected samples to verify the uniformity of the coatings and justify measurements of the samples series using the 
three-location-approach. An attenuated total reflection fourier transform infrared spectroscopy (ATR-FTIR, ThermoElectron Nicolet 6700) was used to collect the infrared spectra. AFM was used as an alternative method for coating thickness by scratching the coating with a steel needle and measuring the profile of the scratch (Figure S8).

The spectra were presented using absorbance mode $\left(-\log R / R_{0}\right)$. The resolution for all the infrared spectra was $4 \mathrm{~cm}^{-1}, 120$ scans for each spectrum.

\subsection{Structural Characterization}

A porometer (Porous Materials Inc., Ithaca, NY, USA) was used to measure the fabric porosity. A capillary flow porometer (CFP) was used to evaluate an average pore diameter, pore size distribution, and mean flow pore size by assessing the relationship between pressure and gas flow rate [69]. The fabrics were cut into circular pieces of $25 \mathrm{~mm}$ in the diameter, soaked into Galwick wetting liquid with the surface tension of 16 Dyne/cm, placed, and sealed into the sample holder for the measurements.

\subsection{Cross-Linking of Nanocellulose Coatings}

The cross-linking was conducted as published elsewhere $[63,64]$, after drying the nanocellulose coatings were treated with $6 \% \mathrm{MA}$ and $4 \% \mathrm{NaH}_{2} \mathrm{PO}_{2}$ solutions and annealed at $185^{\circ} \mathrm{C}$ for $2 \mathrm{~min}$.

\subsection{T-Peel Tests}

The tests were performed according to the method described in the ASTM D1876-08 standard with five tested samples for each material. Samples of the fabrics were cut into $50 \mathrm{~mm} \times 152 \mathrm{~mm}$ stripes along the warp direction. The test panel (Figure S9) consisted of two fabrics stripes bonded together with $5 \mathrm{~g}$ of $2 \%$ NFC or NCC hydrogels along $127 \mathrm{~mm}$ of their length. A $2 \mathrm{~kg}$ load was applied to the top of the test panels while drying at $85^{\circ} \mathrm{C}$. Then, the specimens were placed in a conditioning chamber (Caron ${ }^{\circledR}$ ) for 7 days at a relative humidity of $50 \pm 2 \%$ at $23 \pm 1{ }^{\circ} \mathrm{C}$. Finally, we cut the bonded panels into $25 \mathrm{~mm}$ wide test specimens with a sharp cutter. During the tests, the peeling force was recorded at a constant head speed of $254 \mathrm{~mm} / \mathrm{min}$. The same method for the sample preparation was used for PEI and P(GMA-OEGMA) blended NFC and NCC hydrogels, respectively, as well as for the samples with cross-linked nanocellulose coatings. In the latter case, the samples were annealed at $185^{\circ} \mathrm{C}$ for $2 \mathrm{~min}$. Using ICPeel software [70], we estimated that the bending energy contributions is $15 \%$, which is comparable to the peel test experimental error. Variations in nanocellulose coating thickness in a range of 1-5 $\mu \mathrm{m}$ have a very low effect on the contribution of the bending energy.

\section{Conclusions}

Wet and dry tests of nanocellulose coatings on the surface of cellulose, PET, and nylon (PA 6,6) polymer films revealed that the coatings have the highest adhesion to the nylon, cellulose, and cellophane surfaces, while adhesion is the lowest for the coatings on PET. The coatings stability is improved using treatment with a polycation polymer PEI and a reactive P(GMA-OEGMA) copolymer capable of forming a cross-linked network. In the latter case, the highest coating adhesion and stability were observed. Alternatively, the coating is reinforced by the cross-linking of nanocellulose with polycarboxylic acids. NCC coatings demonstrate higher adhesion to all substrates than NFC coatings. The experiments with cotton, PET, and PA 6,6 fabrics revealed that the fabric structure is an additional important factor for the stability and adhesion of the nanocellulose coatings. The lower density of the textile and higher porosity is beneficial for stronger adhesion of the coatings. Hydrogen bonding, swelling in water, physical, covalent cross-linking, overall contact area, and porosity of the substrate, which provide intercalation of the nanocellulose particles into the fabric structure, are all characteristics that contribute to the nanocellulose coating adhesion and stability. 
Supplementary Materials: The following are available online, Figure S1: Schematics for the multilayered samples of nanocellulose coatings on the surface of polymer materials according to Protocols 1-4, Figure S2: Structure of the P(GMA-OEGMA) copolymer, Figure S3: Pore size distribution of cotton fabrics, Figure S4: Pore size distribution of nylon fabrics, Figure S5: Pore size distribution of cotton/polyester fabrics, Figure S6: Pore size distribution of polyester fabrics, Figure S7: FT-IR spectra of (a) cotton-NCC and cotton-NCC treated with MA and (b) cotton-NFC and cotton- NFC treated with MA, Figure S8: AFM topography image of the cellulose coating on the Si-wafer after the scratch with a steel needle, Figure S9: Schematic of a sample for the T-peel test.

Author Contributions: Conceptualization, S.M., S.S., and I.L.; methodology, S.M., S.S., and I.L.; investigation, R.S., N.B., and A.M.L.; writing-original draft preparation, R.S.; writing—review and editing, S.M. All authors have read and agreed to the published version of the manuscript.

Funding: This research was partially funded by NATO Science for Peace and Security Program under grant G5330, the National Science Foundation via EPSCoR OIA-1655740, and Clemson University Research Foundation.

Conflicts of Interest: The authors declare no conflict of interest.

\section{References}

1. Henriksson, M.; Berglund, L.A. Structure and properties of cellulose nanocomposite films containing melamine formaldehyde. J. Appl. Polym. Sci. 2007, 106, 2817-2824. [CrossRef]

2. Iwamoto, S.; Nakagaito, A.; Yano, H. Nano-fibrillation of pulp fibers for the processing of transparent nanocomposites. Appl. Phys. A Mater. Sci. Process. 2007, 89, 461-466. [CrossRef]

3. Azzam, F.; Moreau, C.L.; Cousin, F.; Menelle, A.; Bizot, H.; Cathala, B. Cellulose nanofibril-based multilayered thin films: Effect of ionic strength on porosity, swelling, and optical properties. Langmuir 2014, 30, 8091-8100. [CrossRef] [PubMed]

4. Kalia, S.; Dufresne, A.; Cherian, B.M.; Kaith, B.; Avérous, L.; Njuguna, J.; Nassiopoulos, E. Cellulose-based bio-and nanocomposites: A review. Int. J. Polym. Sci. 2011, 2011, 1-35. [CrossRef]

5. Daicho, K.; Saito, T.; Fujisawa, S.; Isogai, A. The Crystallinity of Nanocellulose: Dispersion-Induced Disordering of the Grain Boundary in Biologically Structured Cellulose. ACS Appl. Nano Mater. 2018, 1, 5774-5785. [CrossRef]

6. Chakraborty, A.; Sain, M.; Kortschot, M. Cellulose microfibrils: A novel method of preparation using high shear refining and cryocrushing. Holzforschung 2005, 59, 102-107. [CrossRef]

7. Johnson, R.K.; Zink-Sharp, A.; Renneckar, S.H.; Glasser, W.G. A new bio-based nanocomposite: Fibrillated TEMPO-oxidized celluloses in hydroxypropylcellulose matrix. Cellulose 2009, 16, 227-238. [CrossRef]

8. Lavoine, N.; Desloges, I.; Dufresne, A.; Bras, J. Microfibrillated cellulose-Its barrier properties and applications in cellulosic materials: A review. Carbohydr. Polym. 2012, 90, 735-764. [CrossRef]

9. Nishiyama, Y. Structure and properties of the cellulose microfibril. J. Wood Sci. 2009, 55, 241-249. [CrossRef]

10. Wang, S.; Cheng, Q. A novel process to isolate fibrils from cellulose fibers by high-intensity ultrasonication, Part 1: Process optimization. J. Appl. Polym. Sci. 2009, 113, 1270-1275. [CrossRef]

11. Missoum, K.; Belgacem, M.N.; Bras, J. Nanofibrillated cellulose surface modification: A review. Materials 2013, 6, 1745-1766. [CrossRef] [PubMed]

12. Saito, T.; Kimura, S.; Nishiyama, Y.; Isogai, A. Cellulose nanofibers prepared by TEMPO-mediated oxidation of native cellulose. Biomacromolecules 2007, 8, 2485-2491. [CrossRef]

13. Saito, T.; Nishiyama, Y.; Putaux, J.-L.; Vignon, M.; Isogai, A. Homogeneous suspensions of individualized microfibrils from TEMPO-catalyzed oxidation of native cellulose. Biomacromolecules 2006, 7, 1687-1691. [CrossRef] [PubMed]

14. Moon, R.J.; Martini, A.; Nairn, J.; Simonsen, J.; Youngblood, J. Cellulose nanomaterials review: Structure, properties and nanocomposites. Chem. Soc. Rev. 2011, 40, 3941-3994. [CrossRef] [PubMed]

15. Klemm, D.; Kramer, F.; Moritz, S.; Lindström, T.; Ankerfors, M.; Gray, D.; Dorris, A. Nanocelluloses: A new family of nature-based materials. Angew. Chem. Int. Ed. 2011, 50, 5438-5466. [CrossRef] [PubMed]

16. Atalla, R.H.; Brady, J.W.; Matthews, J.F.; Ding, S.Y.; Himmel, M.E. Structures of plant cell wall celluloses. In Biomass Recalcitrance: Deconstructing the Plant Cell Wall for Bioenergy; Wiley-Blackwell: Chichester, UK, 2008; pp. 188-212.

17. Salas, C.; Nypelö, T.; Rodriguez-Abreu, C.; Carrillo, C.; Rojas, O.J. Nanocellulose properties and applications in colloids and interfaces. Curr. Opin. Colloid Interface Sci. 2014, 19, 383-396. [CrossRef] 
18. Habibi, Y.; Lucia, L.A.; Rojas, O.J. Cellulose nanocrystals: Chemistry, self-assembly, and applications. Chem. Rev. 2010, 110, 3479-3500. [CrossRef]

19. Johar, N.; Ahmad, I.; Dufresne, A. Extraction, preparation and characterization of cellulose fibres and nanocrystals from rice husk. Ind. Crops Prod. 2012, 37, 93-99. [CrossRef]

20. Usov, I.; Nyström, G.; Adamcik, J.; Handschin, S.; Schütz, C.; Fall, A.; Bergström, L.; Mezzenga, R. Understanding nanocellulose chirality and structure-properties relationship at the single fibril level. Nat. Commun. 2015, 6, 7564. [CrossRef]

21. Jiang, F.; Hsieh, Y.L. Chemically and mechanically isolated nanocellulose and their self-assembled structures. Carbohydr. Polym. 2013, 95, 32-40. [CrossRef]

22. Zhao, Y.; Simonsen, J.; Cavender, G.; Jung, J.; Fuchigami, L.H. Nano-Cellulose Coatings to Prevent Damage in Foodstuffs. U.S. Patent 10,334,863, 2 July 2019.

23. Vilarinho, F.; Sanches-Silva, A.; Vaz, M.F.; Farinha, J.P. Nanocellulose: A benefit for green food packaging. Crit. Rev. Food Sci. Nutr. 2016, 58, 1526-1537. [CrossRef] [PubMed]

24. Rampazzo, R.; Mascheroni, E.; Fasano, F.; Mari, M.; Piergiovanni, L. Strategies for implementing nano-cellulose coatings in flexible packaging. Ital. J. Food Sci. 2015, 13-17.

25. Li, F.; Biagioni, P.; Bollani, M.; Maccagnan, A.; Piergiovanni, L. Multi-functional coating of cellulose nanocrystals for flexible packaging applications. Cellulose 2013, 20, 2491-2504. [CrossRef]

26. Aulin, C.; Gallstedt, M.; Lindstrom, T. Oxygen and oil barrier properties of microfibrillated cellulose films and coatings. Cellulose 2010, 17, 559-574. [CrossRef]

27. Jabbar, A.; Militký, J.; Wiener, J.; Kale, B.M.; Ali, U.; Rwawiire, S. Nanocellulose coated woven jute/green epoxy composites: Characterization of mechanical and dynamic mechanical behavior. Compos. Struct. 2017, 161, 340-349. [CrossRef]

28. Jiang, F.; Hsieh, Y.L. Amphiphilic superabsorbent cellulose nanofibril aerogels. J. Mater. Chem. A 2014, 2, 6337-6342. [CrossRef]

29. Wang, C.; Li, Y.L.; Hong, F.; Tang, S.J.; Wang, Y.Y. Nano-cellulose coating small-caliber artificial blood vessel. Adv. Mater. Res. 2011, 332, 1794-1798. [CrossRef]

30. Ullah, H.; Santos, H.A.; Khan, T. Applications of bacterial cellulose in food, cosmetics and drug delivery. Cellulose 2016, 23, 2291-2314. [CrossRef]

31. Zhou, J.; Hsieh, Y.L. Nanocellulose aerogel-based porous coaxial fibers for thermal insulation. Nano Energy 2020, 68, 9. [CrossRef]

32. Osong, S.H.; Norgren, S.; Engstrand, P. Processing of wood-based microfibrillated cellulose and nanofibrillated cellulose, and applications relating to papermaking: A review. Cellulose 2016, 23, 93-123. [CrossRef]

33. Carpenter, A.W.; de Lannoy, C.F.; Wiesner, M.R. Cellulose nanomaterials in water treatment technologies. Environ. Sci. Technol. 2015, 49, 5277-5287. [CrossRef]

34. Nemoto, J.; Saito, T.; Isogai, A. Simple freeze-drying procedure for producing nanocellulose aerogel-containing, high-performance air filters. ACS Appl. Mater. Interfaces 2015, 7, 19809-19815. [CrossRef] [PubMed]

35. Tao, X. Handbook of Smart Textiles; Springer: Singapore, 2015.

36. Song, J.H.; Murphy, R.J.; Narayan, R.; Davies, G.B.H. Biodegradable and Compostable Alternatives to Conventional Plastics. Philos. Trans. R. Soc. B-Biol. Sci. 2009, 364, 2127-2139. [CrossRef] [PubMed]

37. Minko, S.; Sharma, S.; Hardin, I.; Luzinov, I.; Daubenmire, S.W.; Zakharchenko, A.; Saremi, R.; Kim, Y.S. Textile Dyeing Using Nanocellulosic Fibers. U.S. Patent US20160010275A1, 29 November 2016.

38. Kim, Y.; McCoy, L.T.; Lee, E.; Lee, H.; Saremi, R.; Feit, C.; Hardin, I.R.; Sharma, S.; Mani, S.; Minko, S. Environmentally sound textile dyeing technology with nanofibrillated cellulose. Green Chem. 2017, 19, 4031-4035. [CrossRef]

39. Liyanapathiranage, A.; Peña, M.J.; Sharma, S.; Minko, S. Nanocellulose-Based Sustainable Dyeing of Cotton Textiles with Minimized Water Pollution. ACS Omega 2020, 5, 9196-9203. [CrossRef] [PubMed]

40. Gardner, D.J.; Oporto, G.S.; Mills, R.; Samir, M.A.S.A. Adhesion and surface issues in cellulose and nanocellulose. J. Adhes. Sci. Technol. 2008, 22, 545-567. [CrossRef]

41. Sinko, R.; Qin, X.; Keten, S. Interfacial mechanics of cellulose nanocrystals. MRS Bull. 2015, 40, 340-348. [CrossRef]

42. d'Eon, J.; Zhang, W.; Chen, L.; Berry, R.M.; Zhao, B.X. Coating cellulose nanocrystals on polypropylene and its film adhesion and mechanical properties. Cellulose 2017, 24, 1877-1888. [CrossRef] 
43. Hossain, L.; Raghuwanshi, V.S.; Tanner, J.; Wu, C.M.; Kleinerman, O.; Cohen, Y.; Garnier, G. Structure and swelling of cross-linked nanocellulose foams. J. Colloid Interface Sci. 2020, 568, 234-244. [CrossRef]

44. Aulin, C.; Ahola, S.; Josefsson, P.; Nishino, T.; Hirose, Y.; Osterberg, M.; Wagberg, L. Nanoscale Cellulose Films with Different Crystallinities and Mesostructures-Their Surface Properties and Interaction with Water. Langmuir 2009, 25, 7675-7685. [CrossRef]

45. Ahola, S.; Salmi, J.; Johansson, L.-S.; Laine, J.; Österberg, M. Model films from native cellulose nanofibrils. Preparation, swelling, and surface interactions. Biomacromolecules 2008, 9, 1273-1282. [CrossRef] [PubMed]

46. Eriksson, M.; Notley, S.M.; Wågberg, L. Cellulose thin films: Degree of cellulose ordering and its influence on adhesion. Biomacromolecules 2007, 8, 912-919. [CrossRef] [PubMed]

47. Fält, S.; Wågberg, L.; Vesterlind, E.-L.; Larsson, P.T. Model films of cellulose ID-improved preparation method and characterization of the cellulose film. Cellulose 2004, 11, 151-162. [CrossRef]

48. Gunnars, S.; Wågberg, L.; Stuart, M.C. Model films of cellulose: I. Method development and initial results. Cellulose 2002, 9, 239-249. [CrossRef]

49. Hoeger, I.; Rojas, O.J.; Efimenko, K.; Velev, O.D.; Kelley, S.S. Ultrathin film coatings of aligned cellulose nanocrystals from a convective-shear assembly system and their surface mechanical properties. Soft Matter 2011, 7, 1957-1967. [CrossRef]

50. Notley, S.M.; Eriksson, M.; Wågberg, L.; Beck, S.; Gray, D.G. Surface forces measurements of spin-coated cellulose thin films with different crystallinity. Langmuir 2006, 22, 3154-3160. [CrossRef] [PubMed]

51. Sczech, R.; Riegler, H. Molecularly smooth cellulose surfaces for adhesion studies. J. Colloid Interface Sci. 2006, 301, 376-385. [CrossRef]

52. Wågberg, L.; Decher, G.; Norgren, M.; Lindström, T.; Ankerfors, M.; Axnäs, K. The build-up of polyelectrolyte multilayers of microfibrillated cellulose and cationic polyelectrolytes. Langmuir 2008, 24, 784-795. [CrossRef]

53. Yokota, S.; Kitaoka, T.; Wariishi, H. Surface morphology of cellulose films prepared by spin coating on silicon oxide substrates pretreated with cationic polyelectrolyte. Appl. Surf. Sci. 2007, 253, 4208-4214. [CrossRef]

54. Savchak, M.; Borodinov, N.; Burtovyy, R.; Anayee, M.; Hu, K.; Ma, R.; Grant, A.; Li, H.; Cutshall, D.B.; Wen, Y.; et al. Highly conductive and transparent reduced graphene oxide nanoscale films via thermal conversion of polymer-encapsulated graphene oxide sheets. ACS Appl. Mater. Interfaces 2018, 10, 3975-3985. [CrossRef]

55. Doszlop, S.; Vargha, V.; Horkay, F. Reactions of epoxy with other functional groups and the arising sec-hydroxyl groups. Periodica Polytechn. Chem. Eng. 1978, 22, 253-275.

56. Cay, A.; Atrav, R.; Duran, K. Effects of warp-weft density variation and fabric porosity of the cotton fabrics on their colour in reactive dyeing. Fibres Text. East. Eur. 2007, 60, 91-94.

57. Allen, T. Non-aqueous ester cross-linking of cotton cellulose. Text. Res. J. 1964, 34, 331-336. [CrossRef]

58. Chen, D.; Yang, C.Q.; Qiu, X. Aqueous polymerization of maleic acid and cross-linking of cotton cellulose by poly (maleic acid). Ind. Eng. Chem. Res. 2005, 44, 7921-7927. [CrossRef]

59. Gagliardi, D.; Shippee, F. Crosslinking of cellulose with polycarboxylic acids. Am. Dyest. Rep. 1963, 52, 74-77.

60. Rowland, S.P.; Welch, C.M.; Brannan, M.A.F.; Gallagher, D.M. Introduction of ester cross links into cotton cellulose by a rapid curing process. Text. Res. J. 1967, 37, 933-941. [CrossRef]

61. Welch, C. Formaldehyde Free Durable Press Finishing in Surface Characterization of Fibres and Textiles; Marcel Dekker: New York, NY, USA, 2000.

62. Welch, C.M. Tetracarboxylic acids as formaldehyde-free durable press finishing agents: Part i: Catalyst, additive, and durability studies. Text. Res. J. 1988, 58, 480-486. [CrossRef]

63. Yang, C.Q.; Chen, D.; Guan, J.; He, Q. Cross-linking cotton cellulose by the combination of maleic acid and sodium hypophosphite. 1. Fabric wrinkle resistance. Ind. Eng. Chem. Res. 2010, 49, 8325-8332. [CrossRef]

64. Yang, C.Q.; Wang, X. Formation of cyclic anhydride intermediates and esterification of cotton cellulose by multifunctional carboxylic acids: An infrared spectroscopy study. Text. Res. J. 1996, 66, 595-603. [CrossRef]

65. Yadavalli, N.S.; Borodinov, N.; Choudhury, C.K.; Quiñones-Ruiz, T.; Laradji, A.M.; Tu, S.; Lednev, I.K.; Kuksenok, O.; Luzinov, I.; Minko, S. Thermal Stabilization of Enzymes with Molecular Brushes. ACS Catalysis 2017, 7, 8675-8684. [CrossRef]

66. Borodinov, N.; Gil, D.; Savchak, M.; Gross, C.E.; Yadavalli, N.S.; Ma, R.; Tsukruk, V.V.; Minko, S.; Vertegel, A.; Luzinov, I. En route to practicality of the polymer grafting technology: One-step interfacial modification with amphiphilic molecular brushes. ACS Appl. Mater. Interfaces 2018, 10, 13941-13952. [CrossRef] [PubMed]

67. McCormick, C.L. Novel Cellulose Solutions. U.S. Patent 4,278,790, 14 July 1981. 
68. McCormick, C.L.; Callais, P.A.; Hutchinson, B.H., Jr. Solution studies of cellulose in lithium chloride and N, N-dimethylacetamide. Macromolecules 1985, 18, 2394-2401. [CrossRef]

69. Mayer, E. Porometry Characterization of Filtration Media. Filtn News 2002, 20, 1-7.

70. Kawashita, L.F.; Moore, D.R. ICPeel Digitised Stress-Strain. Available online: http://www.imperial.ac. uk/media/imperial-college/research-centres-and-groups/adhesion-and-adhesives-group/17285696.XLS (accessed on 8 February 2017).

Sample Availability: Samples of the nanocellulose coatings labeled with reactive dyes are available from the authors for a limited period.

(C) 2020 by the authors. Licensee MDPI, Basel, Switzerland. This article is an open access article distributed under the terms and conditions of the Creative Commons Attribution (CC BY) license (http://creativecommons.org/licenses/by/4.0/). 